University of Warwick institutional repository: http://go.warwick.ac.uk/wrap This paper is made available online in accordance with publisher policies. Please scroll down to view the document itself. Please refer to the repository record for this item and our policy information available from the repository home page for further information.

To see the final version of this paper please visit the publisher's website. Access to the published version may require a subscription.

Author(s): S.K. Nutsugah , J.K. Twumasi , J. Chipili , Y. Sere and S. Sreenivasaprasad Article Title: Diversity of the Rice Blast Pathogen Populations in Ghana and Strategies for Resistance Management

Year of publication: 2009

Link to published version: http://dx.doi.org/10.3923/ppj.2008.109.113

Publisher statement: Open Access

With open access policy, anyone is free to copy, distribute and display the published work provided the article is properly cited. 
Plant Pathology Journal 7 (1): 109-113, 2008

ISSN 1812-5387

(C) 2008 Asian Network for Scientific Information

\title{
Diversity of the Rice Blast Pathogen Populations in Ghana and Strategies for Resistance Management
}

\author{
${ }^{1}$ S.K. Nutsugah, ${ }^{2}$ J.K. Twumasi, ${ }^{3}$ J. Chipili, ${ }^{4}$ Y. Séré and ${ }^{5}$ S. Sreenivasaprasad \\ ${ }^{1}$ Savanna Agricultural Research Institute, P.O. Box 52, Tamale, Ghana \\ ${ }^{2}$ Crops Research Institute, P.O. Box 3785, Kumasi, Ghana \\ ${ }^{3}$ Zambian Ministry of Agriculture, Lusaka, Zambia \\ ${ }^{4}$ Africa Rice Center (WARDA), 01 B.P. 2031, Cotonou, Benin \\ ${ }^{5}$ Warwick HRI, University of Warwick, Warwickshire, CV35 9EF, UK
}

\begin{abstract}
The present study describes the outputs of a collaborative research programme funded by the UK's Department for International Development-Crop Protection Program to investigate the genetic (lineages) and pathogenic (pathotypes) diversity of the blast fungus populations and characterize the key sites suitable for resistance screening. Seventy-one Magnaporthe grisae isolates were collected from seven regions where rice is grown, representing blast populations in Ghana. Following molecular characterization, these isolates were grouped into four distinct lineages designated as GH-1, GH-2, GH-3 and GH-4 and 25 pathotypes. GH-1 was the major lineage comprising $52 \%$ of all the isolates and was present across the country on up to 24 rice cultivars. GH-2 comprising of $30 \%$ of the isolates sampled was restricted in distribution mainly from Hohoe area on up to seven cultivars. GH-3 consisted of six isolates from Western, Eastern and Central Regions while GH-4 consisted of two isolates from Nyankpala in Northern Region. Occurrence of blast pathogen on wild rice and weed hosts has been observed and their potential impact needs to be considered in blast/weed management. Baseline data new to Ghana on the diversity and distribution pattern of the blast pathogen populations have been established and key sites identified. Adaptive research is continuing to develop technologies suitable for long-term pathogen monitoring, identify sources of resistance and develop appropriate blast management strategies.
\end{abstract}

Key words: Blast, lineages, Magnaporthe grisea, Oryza sativa, pathotypes, Ghana

\section{INTRODUCTION}

The demand for rice in Ghana is growing faster than any other staple food. Rice constitutes a major source of calories for the rural and urban people and is cultivated in all the ten regions. During 2003 cropping season, 238,810 metric tons $(\mathrm{m} \mathrm{t}$ ) of paddy rice was produced in Ghana from a land area of 117,720 ha (Anonymous, 2004). The current annual rice import into Ghana is $241,610 \mathrm{~m} \mathrm{t}$, which is equivalent to US $\$ 95.0$ million. The average yield of $2.0 \mathrm{~m} \mathrm{t} /$ ha (Anonymous, 2001) is among the lowest as compared to the rest of the world. A wide range of biophysical constraints reduces the yield potential of the cultivars in all the rice production systems.

Blast disease caused by Pyricularia grisea (syn. P. oryzae) (Rossman et al., 1990) (teleomorph = Magnaporthe grisea (Webster, 1980) remains a threat to rice production worldwide despite extensive research efforts at its control (Teng, 1994). Magnaporthe grisea is able to infect rice at different stages of growth and adapt to both upland and lowland rice ecosystems (Bonman et al., 1992; Teng, 1994). In the West African sub-region, blast is recognised as a primary constraint to rice production causing $3.2-77 \%$ yield losses (Notteghem and Baudin, 1981; Fomba and Taylor, 1994; Singh et al., 2000; Chipili et al., 2003). Deployment of resistant cultivars integrating good cultural practices is the most effective and economical way to combat the blast disease. However, breakdown of resistance is common due to the dynamic nature of the pathogen in responding to the host genotype and environment. Understanding the diversity and dynamics of the pathogen populations and identification of resistance sources based on this knowledge is critical to the development of blast resistance that is stable over space and durable over time.

Corresponding Author: S.K. Nutsugah, Savanna Agricultural Research Institute, P.O. Box 52, Tamale, Ghana Tel: +233-243265430/208163733, +233-71-91205 
In this context, the West Africa Rice Development Association (WARDA), Benin, Savanna Agricultural Research Institute (SARI) and Crops Research Institute (CRI), Ghana and Warwick HRI (previously Horticulture Research International), UK have been involved in a collaborative strategic research program funded by the UK Department for International Development (DFD)-Crop Protection Programme (CPP). The objectives were to characterize the resistance screening sites, assess the genetic and pathogenic diversity of pathogen populations and identify potential resistance sources. This study describes the blast population and screening site characterization aspects based on the work done at Warwick HRI in co-ordination with WARDA, SARI and CRI.

\section{MATERIALS AND METHODS}

Blast samples were collected from rice screening sites and surrounding locations in Ghana from 2000-2002 and sent to Warwick HRI, UK for MGR586 fingerprint pattern or lineage determination and pathotype analysis. In all, seventy-one $M$. grisea isolates were obtained from the blast samples collected and characterized (Chipili, 2000; Chipili et al., 2002). DNA was extracted from mycelial powder by the CTAB method (Valent et al., 1991; Hamer and Givan, 1990; Sreenivasaprasad, 2000). DNA digestion and Southern hybridisation with the MGR586 probe were carried out following standard protocols (Levy et al., 1991). Virulence spectrum of the $M$. grisea isolates was determined on the international differential set of rice cultivars following the scale of Valent et al. (1991) and pathotype designations were assigned based on Ling and Ou (1969).

\section{RESULTS AND DISCUSSION}

Seventy-one $M$. grisea isolates collected from seven rice producing regions, Ashanti, Central, Eastern, Northern, Upper East, Volta and Western, were grouped into four distinct lineages (genetic groups) designated as GH-1, GH-2, GH-3 and GH-4 (Table 1). GH-1 was the major lineage comprising $52 \%$ of all the isolates and was present in all but one of the region (Eastern) where isolates were collected. Lineage GH-1 occurred on at least 24 rice cultivars some of which could have related genetic background, for example Tox-related cultivars. Lineage GH-2 comprised $30 \%$ of the isolates sampled and except for three isolates from Asikam (Eastern), Kpachie and Galenkpegu (both from Northern) all were from the Hohoe area in the Volta Region recovered from seven different rice cultivars (two of which were Tox-related) and one weed host at Santrokofi \# 7. Lineage GH-3 consisted of six isolates (8\%) from Agya-Amoa (Sayerano, Nsuansua and Sefwi-Wiawso in Western), red rice in Otumi (Eastern) and Diaso (Central). Isolates B18 and B137 from unknown rice cultivars in Tono \# 1 (Upper East) and Nyankpala \# 1 (Northern), respectively formed lineage GH-4 (3\%). Further, five $M$. grisea isolates from Tanoso (Western), Otumi \# 2 (Eastern), Kwadaso \# 4 (Ashanti) and Tono \# 3 (Upper East) from elephant grass, wild rice and known/unknown rice cultivars produced 'atypical' fingerprints (non-rice pathogen-like MGR586 fingerprints) (Borromeo et al., 1993).

The virulence characteristics of the representative isolates were determined on the international rice differentials. Twenty-five pathotypes were recorded from more than 20 rice cultivars and also from a weed and wild rice across the seven rice producing regions (Table 1). Volta with 12 pathotypes and Upper East with eight were most diverse. A number of isolates showed distinct virulence spectrum defined by a particular pathotype, but there were also examples where different isolates belonged to the same pathotype. For example, IB-1 was recorded in all the regions except Eastern. Isolates 5038 and 60040 from weed hosts were pathogenic on the international rice differentials (Chipili et al., 2003). The most frequently observed pathotype groups were IB and IC (Table 1 and 2).

Analysis of the lineage-pathoytype data has provided some understanding of the lineage-pathotype relationships. Pathotypes represented in lineage GH-1 were mostly IB group. Some of the other isolates in this lineage originating from Tox-related cultivars at Hohoe also expressed related pathotypes. Similarly, pathotypes represented in lineage GH-2 were mostly IB group. Lineage GH-3 represented diverse pathotypes from groups IA, IB, IC, ID, IF and IH (Table 2).

Based on the diversity and distribution of the blast genetic groups (lineages) and pathotypes (Table 1 and 2), various key sites have been identified to be suitable for blast resistance screening. Hohoe in Volta Region with major lineages $\mathrm{GH}-1$ and $\mathrm{GH}-2$ and 12 pathotypes belonging to five pathotype groups (IA, IB, IC, ID and IG) is a high diversity site. In the North, Nyankpala and Bolgatanga with lineages GH-1, GH-2 and GH-4 and 12 pathotypes (IA, IB and IC groups) were characterized. Although six pathotypes belonging to groups IA, IB, IC and ID were recorded in Western Region (Sayerano and Sefwi-Wiawso) one of the major lineages GH-2 was not observed, which needs to be further monitored. At 
Plant Pathol. J., 7 (1): 109-113, 2008

Table 1: Details of site, host cultivar, lineage grouping and pathotype designation of Magnoporthe grise $a$ isolates from Ghana

\begin{tabular}{|c|c|c|c|c|}
\hline Code & Location $^{1}$ & Host cultivar $^{2}$ & Lineage $^{3}$ & Pathotype $^{4}$ \\
\hline \multicolumn{5}{|c|}{ Ashanti region } \\
\hline B115 & Kwadaso \# 1 & WAB 638-9-A36 & GH-1 & IB-1 \\
\hline B119 & Kwadaso \# 2 & WAB $651-B-A-158$ & GH-1 & ID-13 \\
\hline B124 & Kwadaso \# 3 & WAB 651-B-9-B36 & GH-1 & IB-45 \\
\hline B336 & Kwadaso \#4 & WAB 638-9-H36 & Atypical $^{5}$ & -6 \\
\hline 60059 & Aframso & More & GH-1 & IB-1 \\
\hline 60060 & Dromankoma & More & GH-1 & ID-1 \\
\hline 60061 & Offinso-Kayera & Asante-mo & GH-1 & IB-13 \\
\hline 60062 & Any inasuso & Asante-mo & GH-1 & IB-1 \\
\hline \multicolumn{5}{|c|}{ Central region } \\
\hline $6007 a$ & Diaso \# 1 & Local & GH-1 & IC-1 \\
\hline $6007 \mathrm{~b}$ & Diaso \# 2 & Local & GH-3 & IH-1 \\
\hline $6007 \mathrm{c}$ & Diaso \# 3 & Local & GH-3 & IB-9 \\
\hline $60012 a$ & Abora \# 1 & Red rice & GH-1 & IB-1 \\
\hline $60012 b$ & Abora \#2 & Red rice & GH-1 & IB-1 \\
\hline $60012 c$ & Abora \#3 & Red rice & GH-1 & IC-9 \\
\hline \multicolumn{5}{|c|}{ Eastern region } \\
\hline $60021 b$ & Otumi \# 1 & Red rice & GH-3 & ID-9 \\
\hline $60021 \mathrm{c}$ & Otumi \# 2 & Red rice & Atypical & IC-13 \\
\hline 60035 & Asikam & Red rice & GH-2 & IC- 25 \\
\hline \multicolumn{5}{|c|}{ Western region } \\
\hline 5010 & Sayerano\# 1 & Agya-Amoa & GH-3 & IC-9 \\
\hline 5082 & Sefwi-Wiawso & Agya-Amoa & GH-3 & IA -9 \\
\hline 5083 & Sayerano\# 2 & Agya-Amoa & GH-1 & IB-45 \\
\hline $60013 a$ & Nsuansua & Agya-Amoa & GH-3 & IF-1 \\
\hline 60025 & Tanoso & Elephant grass & Atypical & II-1 \\
\hline 60063 & Adjakaa-Manso & Wassa-mo & GH-1 & ID-13 \\
\hline \multicolumn{5}{|c|}{ Volta region } \\
\hline B147 & Hohoe \# 1 & Tox 3100-37-3-3-2-9 & GH-2 & IB-61 \\
\hline B149 & Hohoe \# 2 & TGR 75 & GH-2 & IB-21 \\
\hline B150 & Hohoe \# 3 & ITA 321 & GH-2 & IB-61 \\
\hline B151 & Hohoe \# 4 & Tox 3416-170-2-1-1 & GH-1 & - \\
\hline B152 & Hohoe \# 5 & TCA $80-4$ & GH-2 & IB-13 \\
\hline B153 & Hohoe \# 6 & Tox 3880-38-1-1-2 & GH-1 & $\mathrm{IA}-2$ \\
\hline B154 & Hohoe \# 7 & WAB 450-24-3-2-P18-HB & GH-1 & IB-1 \\
\hline B157 & Hohoe \# 8 & WAB-IR-12979 & GH-1 & IB-1 \\
\hline B158 & Hohoe \# 9 & CK 73 & GH-2 & IB-9 \\
\hline B159 & Hohoe \#10 & Tox 3792-10-1-2-1-1-3-2 & GH-1 & IB-1 \\
\hline B161 & Hohoe \# 11 & Tox $3100-37-3-3-2-4$ & GH-2 & IB-13 \\
\hline B163 & Hohoe \#12 & WAB 340-B-B-9-L3-L1-LB & GH-1 & IB-5 \\
\hline B164 & Hohoe \#13 & Tox 728-1 & GH-1 & IB-1 \\
\hline B165 & Hohoe \#14 & Tox 3440-171-1-1-1 & GH-1 & IB-7 \\
\hline B167 & Hohoe \#15 & Tox 4004-43-1-2-1 & GH-1 & IA-1 \\
\hline 5008 & Gbi-Godenu \#1 & Viwono & GH-2 & IB-61 \\
\hline 5009 & Gbi-Godenu \#2 & Viwono & GH-2 & IB-61 \\
\hline 5079 & Santrok ofi \# 1 & Viwono & GH-1 & IB-1 \\
\hline 5081 & Gbi-Godenu \#3 & Viwono & GH-1 & IB-1 \\
\hline $6005 \mathrm{a}$ & Fodome\# 1 & Viwono & GH-2 & ID-13 \\
\hline $6005 \mathrm{~b}$ & Fodome \# 2 & Viwono & GH-2 & IB-61 \\
\hline $6005 c$ & Fodome \# 3 & Viwono & GH-2 & - \\
\hline $6005 \mathrm{~d}$ & Fodome\#4 & Viwono & GH-2 & IC-1 \\
\hline $6009 a$ & Santrokofi \# 2 & Viwono & GH-2 & IB-1 \\
\hline $6009 \mathrm{~b}$ & Santrok of $\#$ \# 3 & Viwono & GH-2 & - \\
\hline $6009 \mathrm{c}$ & Santrok ofi \# 4 & Viwono & GH-2 & IB-1 \\
\hline $60011 \mathrm{a}$ & Santrok ofi \# 5 & Viwono & GH-2 & IB-61 \\
\hline $60011 \mathrm{~b}$ & Santrokofi \# 6 & Viwono & GH-2 & IG-1 \\
\hline $60019 b$ & Kpoeta \# 1 & Perfume rice & GH-1 & IB-5 \\
\hline $60019 \mathrm{c}$ & Kpoeta\# 2 & Perfume rice & GH-1 & IB-1 \\
\hline 60040 & Santrok ofi \# 7 & Weed & GH-2 & IG-1 \\
\hline \multicolumn{5}{|c|}{ Northern region } \\
\hline $\mathrm{B} 137$ & Nyankpala \# 1 & Unknown & GH-4 & - \\
\hline 60046 & Ny ankpala \# 2 & Mendi & GH-1 & IB-1 \\
\hline 60051 & Golinga & Agongima & GH-1 & IB-9 \\
\hline 60053 & Galenkpegu & More & GH-2 & IB-13 \\
\hline 60054 & Kpachie & Local rice & GH-2 & IC-29 \\
\hline 60055 & Salaga & Tox 3050 & GH-1 & IB-9 \\
\hline
\end{tabular}




\begin{tabular}{|c|c|c|c|c|}
\hline Code & Location $^{1}$ & Host cultivar $^{2}$ & Lineage $^{3}$ & Pathotype $^{4}$ \\
\hline \multicolumn{5}{|c|}{ Upper east region } \\
\hline B18 & Tono\# 1 & Unknown & $\mathrm{GH} 4$ & IC-17 \\
\hline B175 & Bolgatanga \# 1 & Red rice & GH-1 & - \\
\hline B179 & Bolgatanga \# 2 & Red rice & GH-1 & IC-13 \\
\hline B200 & Bolgatanga \# 3 & Red rice & GH-1 & IA-88 \\
\hline B201 & Bolgatanga \# 4 & Red rice & GH-1 & IC-25 \\
\hline B202 & Bolgatanga \# 5 & Red rice & GH-1 & IB-1 \\
\hline B236 & Bolgatanga \# 6 & Red rice & GH-1 & - \\
\hline 5033 & Tono \# 2 & Unknown & Atypical & IC-29 \\
\hline 5038 & Tono\# 3 & Wild rice & Atypical & IB-29 \\
\hline 60056 & Nyorigu \# 1 & Local rice & GH-1 & IC-9 \\
\hline 60057 & Nyorigu \# 2 & More & GH-1 & IB-1 \\
\hline
\end{tabular}

Table 2: Pathotype designation and lineage grouping of Magnoporthe grisea isolates from Ghana

\begin{tabular}{|c|c|c|c|c|c|}
\hline \multirow[b]{2}{*}{ Pathotype } & \multicolumn{5}{|c|}{ Lineage } \\
\hline & GH-1 & GH-2 & GH-3 & GH-4 & Atypical $^{1}$ \\
\hline$\overline{\mathrm{IA}-1}$ & + & & & & \\
\hline IA-2 & + & & & & \\
\hline IA -9 & & & + & & \\
\hline IA-88 & + & & & & \\
\hline IB-1 & + & + & & & \\
\hline IB-5 & + & & & & \\
\hline IB-7 & + & & & & \\
\hline IB-9 & + & + & + & & \\
\hline IB-13 & + & + & & & \\
\hline IB-21 & & + & & & \\
\hline IB-25 & & & & & + \\
\hline IB-45 & + & & & & \\
\hline IB-61 & & + & & & \\
\hline IC-1 & + & + & & & \\
\hline IC-9 & + & & + & & \\
\hline IC-13 & + & & & & \\
\hline IC-17 & & & & + & \\
\hline IC-25 & + & + & & & \\
\hline IC-29 & & + & & & \\
\hline ID-1 & + & & & & \\
\hline ID-9 & & & + & & \\
\hline ID-13 & + & + & & & \\
\hline IF-1 & & & + & & \\
\hline IG-1 & & + & & & \\
\hline IH-1 & & & + & & \\
\hline TOTAL & 15 & 10 & 6 & 1 & 1 \\
\hline
\end{tabular}

${ }^{1}$ : Magnaporthe grisea isolates from wild rice produced atypical fingerprint patterns with few (up to 9) MGR586 hybridising bands (Borromeo et al., 1993)

Bolgatanga, pathotypes IA-88, IC-13, IC-25 and IB-1 were recorded from red rice, indicating the susceptibility of this type of rice to a wider range of pathotypes. On the other hand, there were examples where the same pathotype occurred on different cultivars; IB-1 from two Tox-related varieties from Hohoe and a third red rice variety from Bolgatanga. This suggests that the host genetic background could be related and/or that common genetic factors could be governing these interactions. Screening of a range of rice cultivars under controlled conditions against 15 Ghanaian blast lineage representatives and at some of the characterized sites has led to the identification of potential blast resistances (Nutsugah et al., 2005) that need to be further tested and/or developed.

The distribution pattern of the $M$. grisea lineages varied (Table 1) across the rice producing regions in Ghana. For instance lineage GH-1 was found in all regions except Eastern, while GH-2 and GH-3 tended to be more site specific. This suggests that the agro-environmental conditions, particularly the host genotypes present influence the shape of the pathogen population.

The blast characterization work has identified the occurrence of blast pathogen on wild rice and weed hosts common in the rice farming systems. Several of these isolates are closely related to rice pathogenic isolates in their genetic profile and are pathogenic on rice under controlled conditions (Chipili et al., 2003). The epidemiological significance of these isolates and their impact on blast management merit further investigation.

Baseline data on the diversity and distribution pattern of the pathogen populations in Ghana has been established and key screening sites identified. SARI and $\mathrm{CRI}$ are continuing with adaptive research to understand the dynamics of the blast pathogen populations, develop technologies suitable for long-term local monitoring of blast, identify sources of resistance to characterised pathogen groups and develop appropriate blast management strategies.

\section{ACKNOWLEDGMENTS}

The research was supported by DFID-CPP managed by the Natural Resources International, UK through Project R7552 coordinated by Dr. S. Sreenivasaprasad. The MGR586 probe was kindly provided by Dr. J.E. Hamer, Purdue University/Paradigm Genetics, USA. The authors wish to express their gratitude to the field technical staff for their assistance. 


\section{REFERENCES}

Anonymous, 2001. Agriculture in Ghana, Facts and Figures. The Statistics, Research and Information Directorate, MOFA, Accra, Ghana, pp: 39.

Anonymous, 2004. Production and Cropped Area for Major Crops in Ghana-2003. Statistics, Research and Information Directorate (SRD) MOFA, Accra, Ghana.

Bonman, J.M., G.S. Khush and R.J. Nelson, 1992. Breeding rice for resistance to pests. Annu. Rev. Phytopathol., 30: $507-528$.

Borromeo, E.S., R.J. Nelson, J.M. Bonman and H. Leung, 1993. Genetic differentiation among isolates of Pyricularia infecting rices and weed hosts. Phytopathology, 83: 393-399.

Chipili, J., 2000. Characterisation of populations of Magnaporthe grisea, the rice blast fungus, in some of the West African countries. Ph.D Thesis, University of Exeter, UK., pp: 130.

Chipili, J., S. Sreenivasaprasad, Y. Séré, S.K. Nutsugah, J. Twumasi, A.E. Brown and N.J. Talbot, 2002. Blast pathogen population diversity in West Africa and strategies for achieving durable resistance. Proceedings of the 2nd Regional Rice Research Review. 9-12 April 2002, Bouaké, Côte d' Ivoire.

Chipili, J., S. Sreenivasaprasad, S.K. Nutsugah, J.K. Twumasi and K. Dartey, 2003. Rice blast management in Ghana: Characterization of the pathogen diversity. J. Ghana Sci. Assoc., 5: 20-25.

Fomba, S.N. and D.R. Taylor, 1994. Rice Blast in West Africa: Its Nature and Control. In: Rice Blast Disease. Zeigler, R.S., S.A. Leong and P.S. Teng (Eds.), CAB International, Wallingford, Oxon, UK and International Rice Research Institute, Manilla, The Philippines, pp: 343-355.

Hamer, J.E. and S. Givan, 1990. Genetic-mapping with dispersed repeated sequences in the rice blast fungus-mapping the Smo locus. Mol. General Genet, 223: 487-495.
Levy, M., J. Romao, M.A. Marchetti and J.E. Hamer, 1991. DNA fingerprinting with a dispersed repeated sequence resolves pathogen diversity in the rice blast fungus. Plant Cell, 3: 95-102.

Ling, K.C. and S.H. Ou, 1969. Standardization of the international race numbers of Pyricularia oryzae. Phytopathology, 59: 339-342.

Notteghem, J.L. and P. Baudin, 1981. Main Rice Diseases in West Africa. West Africa Rice Development Association, Monrovia, Liberia.

Nutsugah, S.K., W. Dogbe, J.K. Twumasi, K. Dartey, J. Chipili, S. Sreenivasaprasad and Y. Séré, 2005. Prevalence of rice blast and varietal screening in Ghana. J. Sci. Technol., 25: 18-34.

Rossman, A.Y., R.J. Howard and B. Valent, 1990. Pyricularia grisea, the correct name for the rice blast disease fungus. Mycologia, 82: 509-512.

Singh, B.N., M.P. Jones, S.N. Fomba, Y. Séré, A.A. Sy, K. Akator, P. Ngninbeyie and S.W. Ahn, 2000. Breeding for Blast Resistance in Lowland Rice in West Africa. In: Advances in Rice Blast Research. Tharreau, D., M.H. Lebrun, N.J. Talbot and J.L. Notteghem (Eds.), Kluwer Academic, The Netherlands, pp: 112-128.

Sreenivasaprasad, S., 2000. Isolation of Fungal Nucleic Acids. In: Nucleic Acids Protocols Handbook. Rapley, R. and J.M. Walker (Eds.), Humana Press, USA., pp: 37-45.

Teng, P.S., 1994. The Epidemiological Basis for Blast Management. In: Rice Blast Disease. Zeigler, R.S., S.A. Leong and P.S. Teng (Eds.), CAB International, Wallingford, Oxon, UK and International Rice Research Institute, Manila. The Philippines, pp: 409-433.

Valent, B., L. Farrall and F.G. Chumley, 1991. Magnaporthe grisea genes for pathogenicity and virulence identified through a series of back crosses. Genetics, 127: 87-101.

Webster, J., 1980. Introduction to Fungi. 2nd Edn., Cambridge University Press, Cambridge, UK. 